\title{
SECONDARY SYMMETRY OF ASYMMETRIC GENITALIA IN MALES OF ERYNNIS FUNERALIS AND E. PROPERTIUS (LEPIDOPTERA: HESPERIIDAE)
}

\author{
By John M. Burns \\ Museum of Comparative Zoology, Harvard University
}

The form of the genitalia is extraordinarily useful for distinguishing species in many animal groups, and nowhere more so than in the Lepidoptera. Indeed, in various genera - including some of those in Evans' (1953) "Erynnis Group" of American pyrgine hesperiids - the genitalia have become asymmetric so that the number of potential, taxonomically valuable characters is about doubled. Asymmetry of this kind was first described a century ago (Scudder and Burgess 1870) in males of Erynnis, where it is very pronounced.

Out of 12,000 specimens whose genitalia I have examined in the course of microevolutionary studies of Erynnis (Burns 1964 and unpublished), two individuals have genitalia so deviant yet so harmoniously formed as almost to suggest new species. Both are males of Erynnides, a subgenus in which the valvae (or claspers) are characterized as "always highly asymmetric" (Burns 1964: 24); however, both "show striking secondary symmetry of the genitalia, in which the left valva is not its distinctive self, but instead, a mirror image of the right valva" (Burns 1964: 9). These variants belong to two of the species - Erynnis funeralis and E. propertius - that were described as new by Scudder and Burgess ( 1870 ) solely on the basis of morphologic differences in the asymmetric genitalia of males.

In figs. I-4, the symmetric valvae of the "half-wrong" variants are directly compared with their standard asymmetric counterparts. The secondarily established symmetry is extremely good in $E$. $f u$ neralis (fig. 2) but rather less exact in E. propertius (fig. 4) in which, for example, the distal ends of the ventral processes do not agree in detail. Clearly, there is no reversion here to some ancestral symmetric condition: in both E. funeralis (cf. figs. I and 2) and E. propertius (cf. figs. 3 and 4 ), the right valva in the symmetric variant precisely retains its modern shape, and it is this shape that the left valva duplicates.

Both variants appear to have stemmed from developmental quirks. Experimental analyses of insect morphogenesis (see e.g. Ursprung 
1963) suggest the following general explanation. In the course of differentiation, cells destined to produce the left valva were damaged; and the organism regulated with a contribution from corresponding cells of the right side. These were already determined for right valval morphology. But, in their new location on the left, they made a structure that assumed the proper functional orientation. Thus a mirror image of the right valva emerged.

Regulation of this kind, detectable when it overturns asymmetry, would never reveal itself in most species because the genitalia are symmetric from the beginning.

\section{AcKNowledgements}

I thank M. P. Kambysellis and J. H. Postlethwait for reading the manuscript, and R. G. Gillmor for drawing the figures. This work was supported in part by grants from the National Science Foundation (GB 5935) and the William F. Milton Fund of Harvard University.

Burns, J. M.

\section{Literature Cited}

1964. Evolution in skipper butterflies of the genus Erynnis. Univ. California Publ. Entomol. 37: 216 pp., 1 pl.

Evans, W. H.

1953. A catalogue of the American Hesperiidae indicating the classification and nomenclature adopted in the British Museum ( Natural History). Part III. Pyrginae. Sec. 2. London: British Museum. 246 pp., pls. 26-53.

ScUdDER, S. H. and E. BURGESS

1870. On asymmetry in the appendages of hexapod insects, especially as illustrated in the lepidopterous genus Nisoniades. Proc. Boston URSPRUNG, H. Soc. Nat. Hist. 13 : 282-306, 1 pl.

1963. Development and genetics of patterns. Am. Zoologist 3: 71-86. 

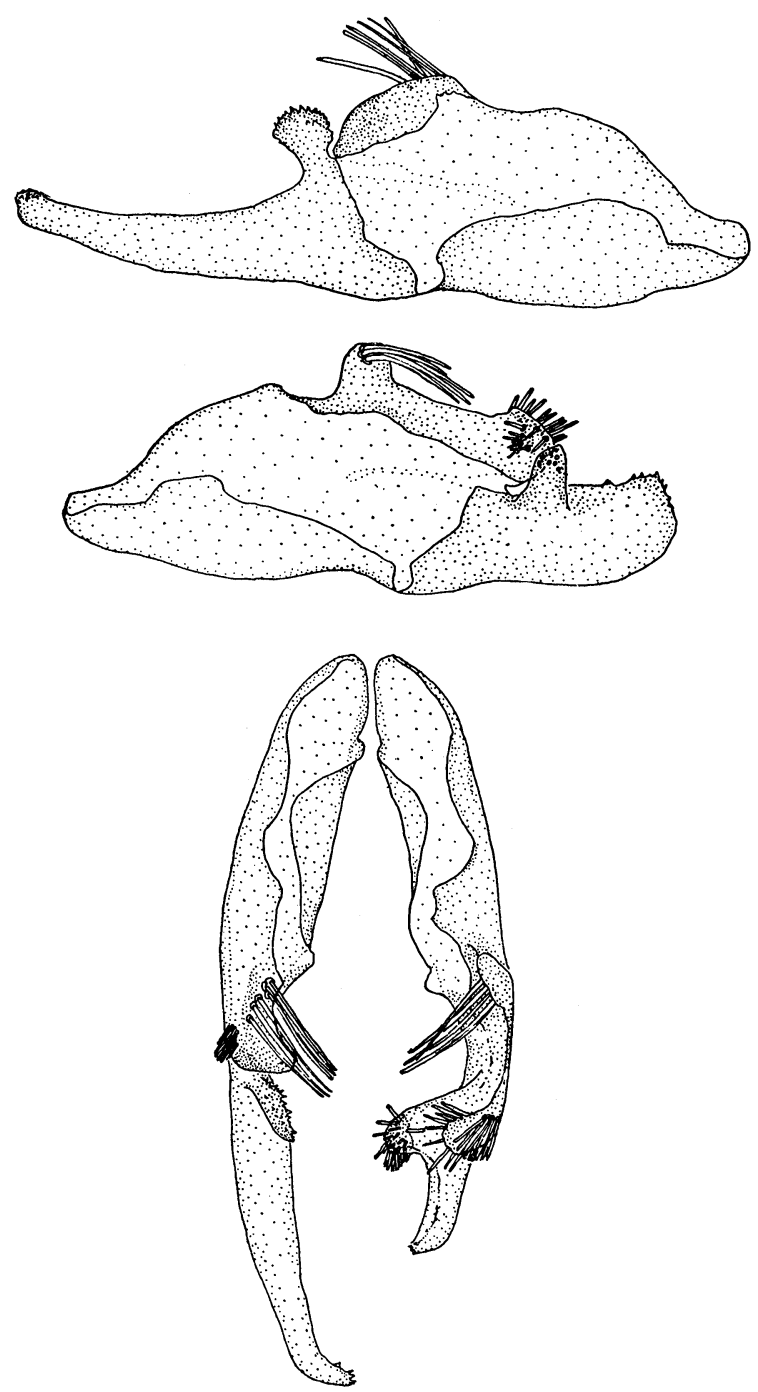

Fig. 1. Normal asymmetric male genitalia of Erynnis funeralis. Top: Medial view of left valva. Middle: Medial view of right valva. Bottom: Dorsal view of both valvae. (Specimen from Southwestern Research Station of the American Museum of Natural History, Cave Creek Canyon, 5400 ft., Chiricahua Mountains, Cochise County, Arizona, VII-4-1958, J. M. and S. N. Burns.) 

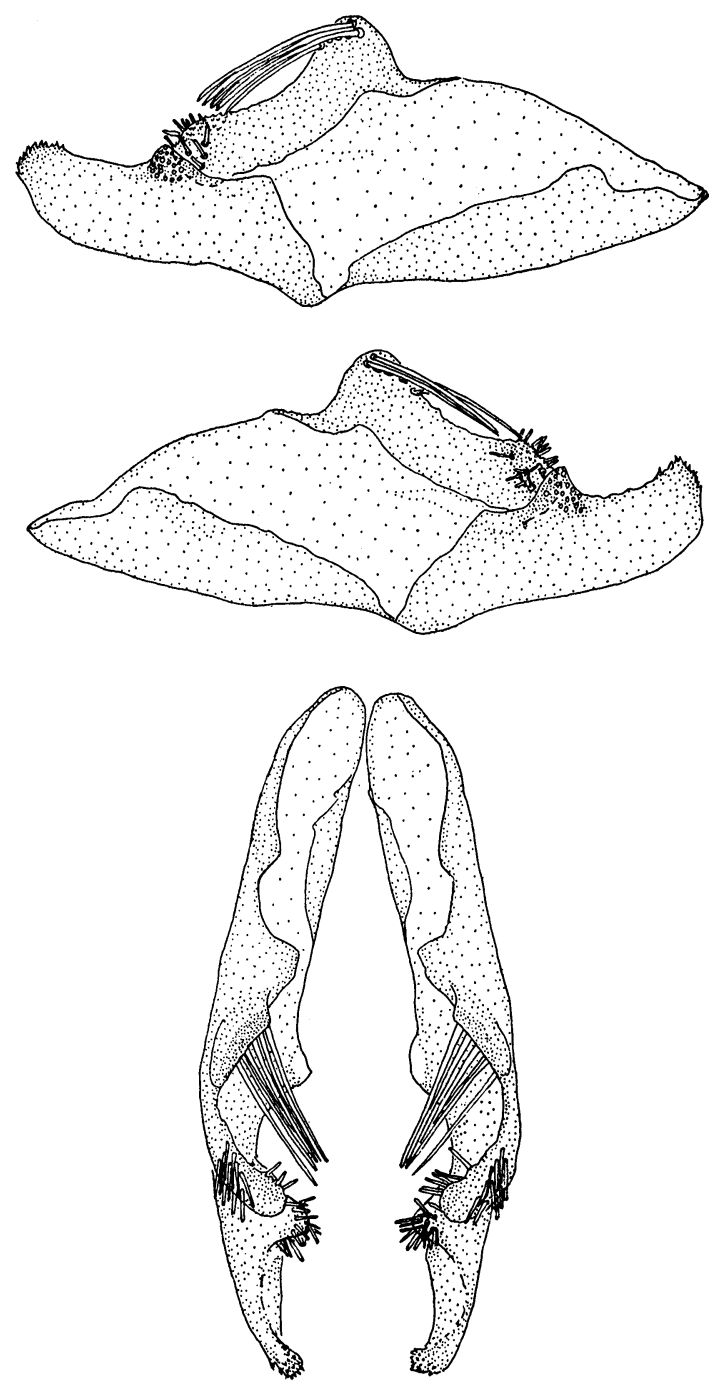

Fig. 2. Abnormal symmetric male genitalia of Erynnis funeralis. Arranged as in fig. 1. (Specimen supposedly from "Fla." [no date, no collector].) 

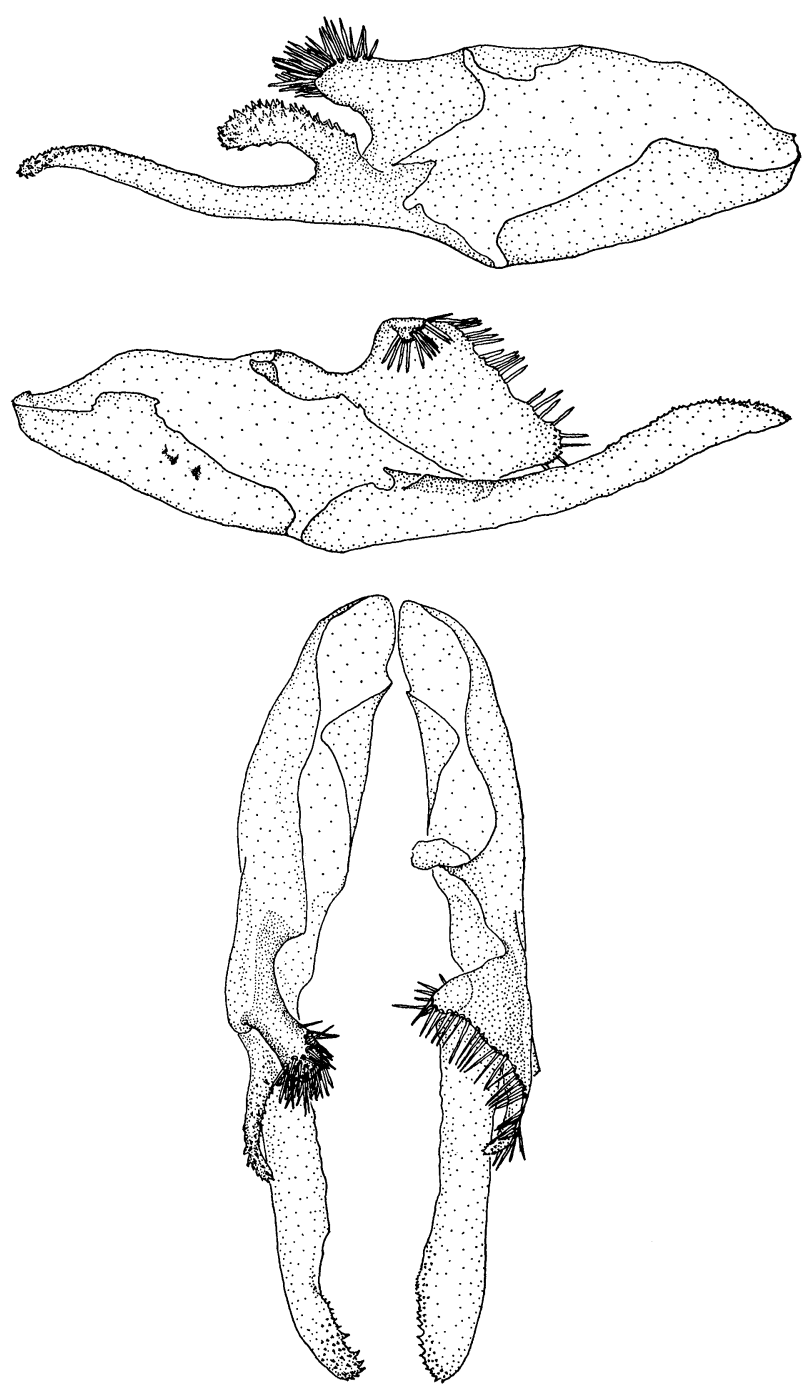

Fig. 3. Normal asymmetric male genitalia of Erynnis propertius. Arranged as in fig. 1. (Specimen from Arroyo Seco, Monterey County, California, V-23-1958, D. D. Linsdale.) 

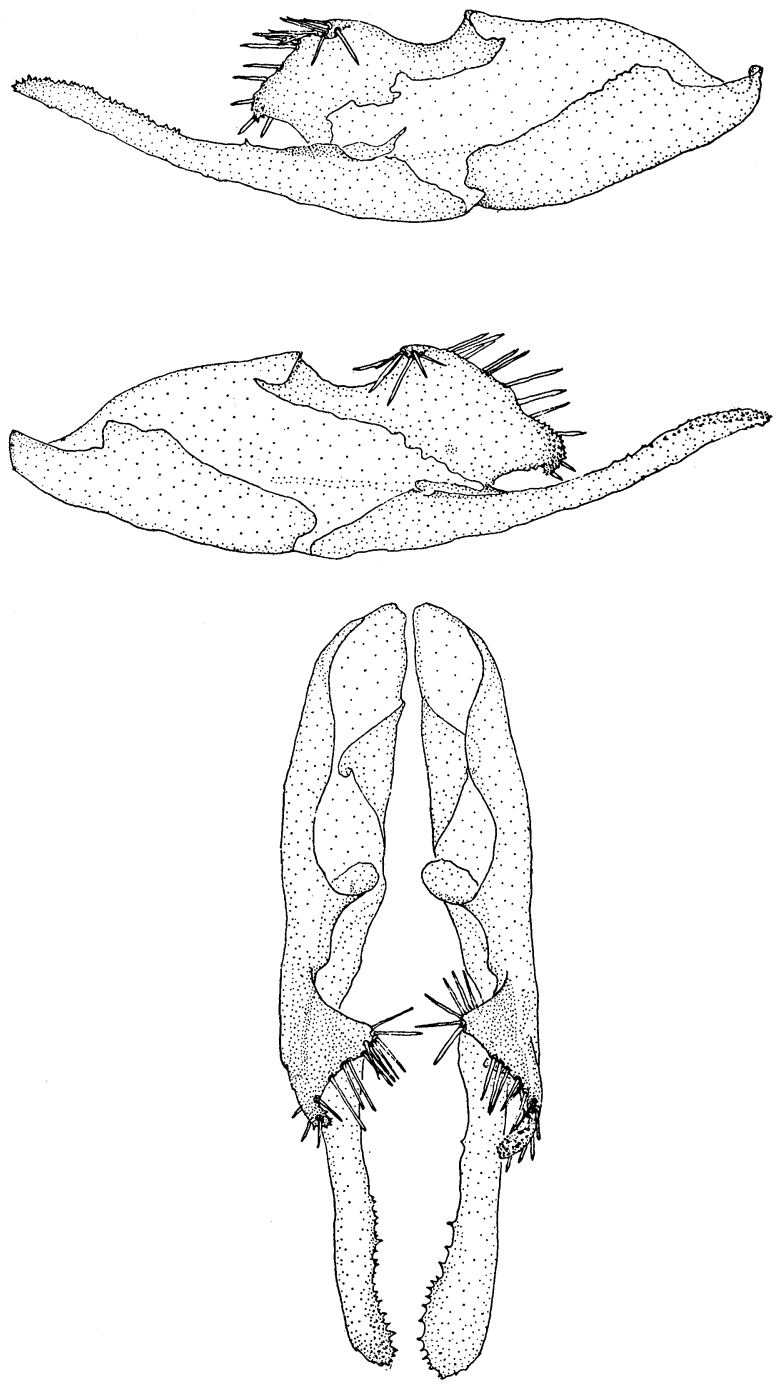

Fig. 4. Abnormal symmetric male genitalia of Erynnis propertius. Arranged as in fig. 1. (Specimen from Victoria, British Columbia, IV-19-1903 [no collector].) 

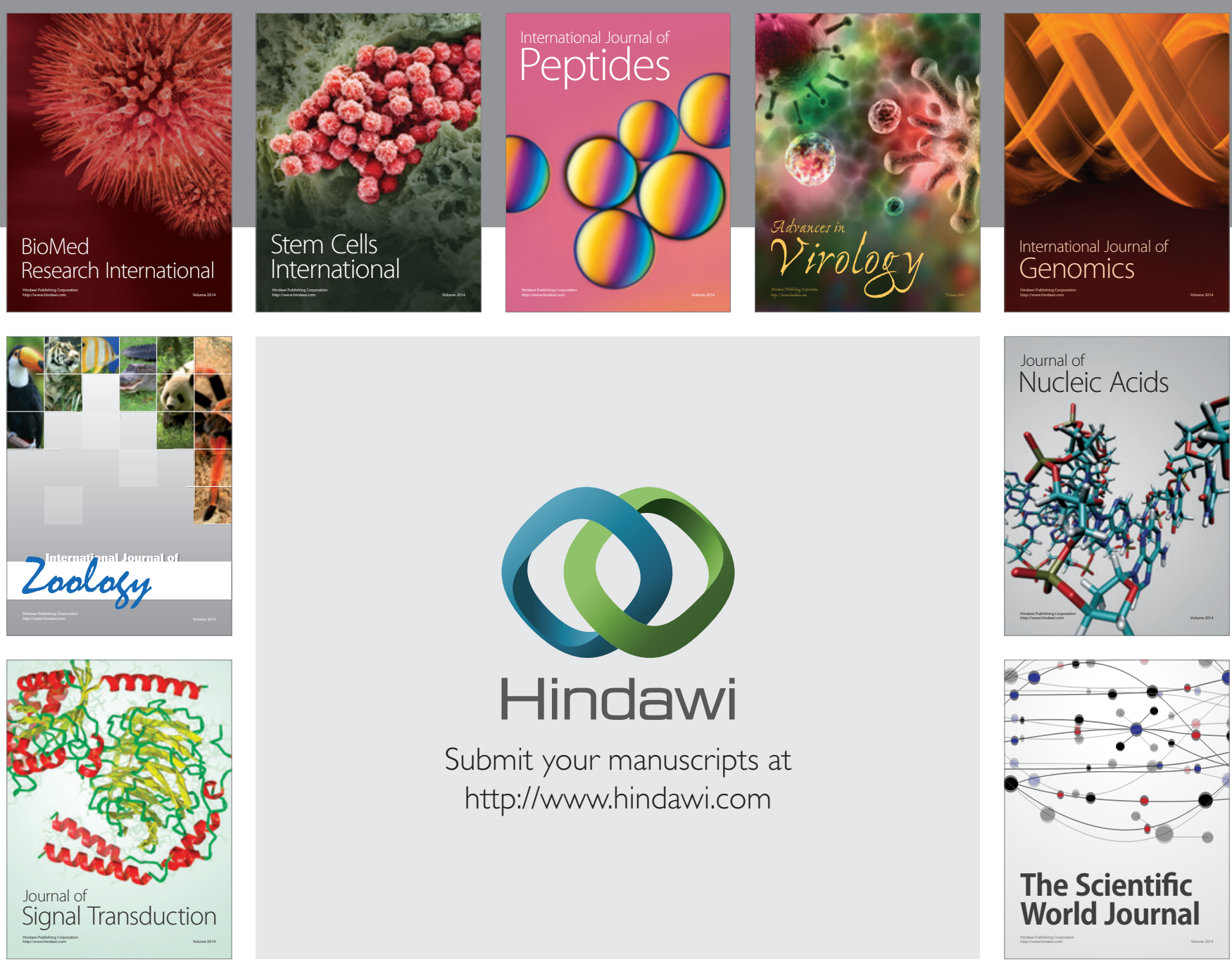

Submit your manuscripts at

http://www.hindawi.com
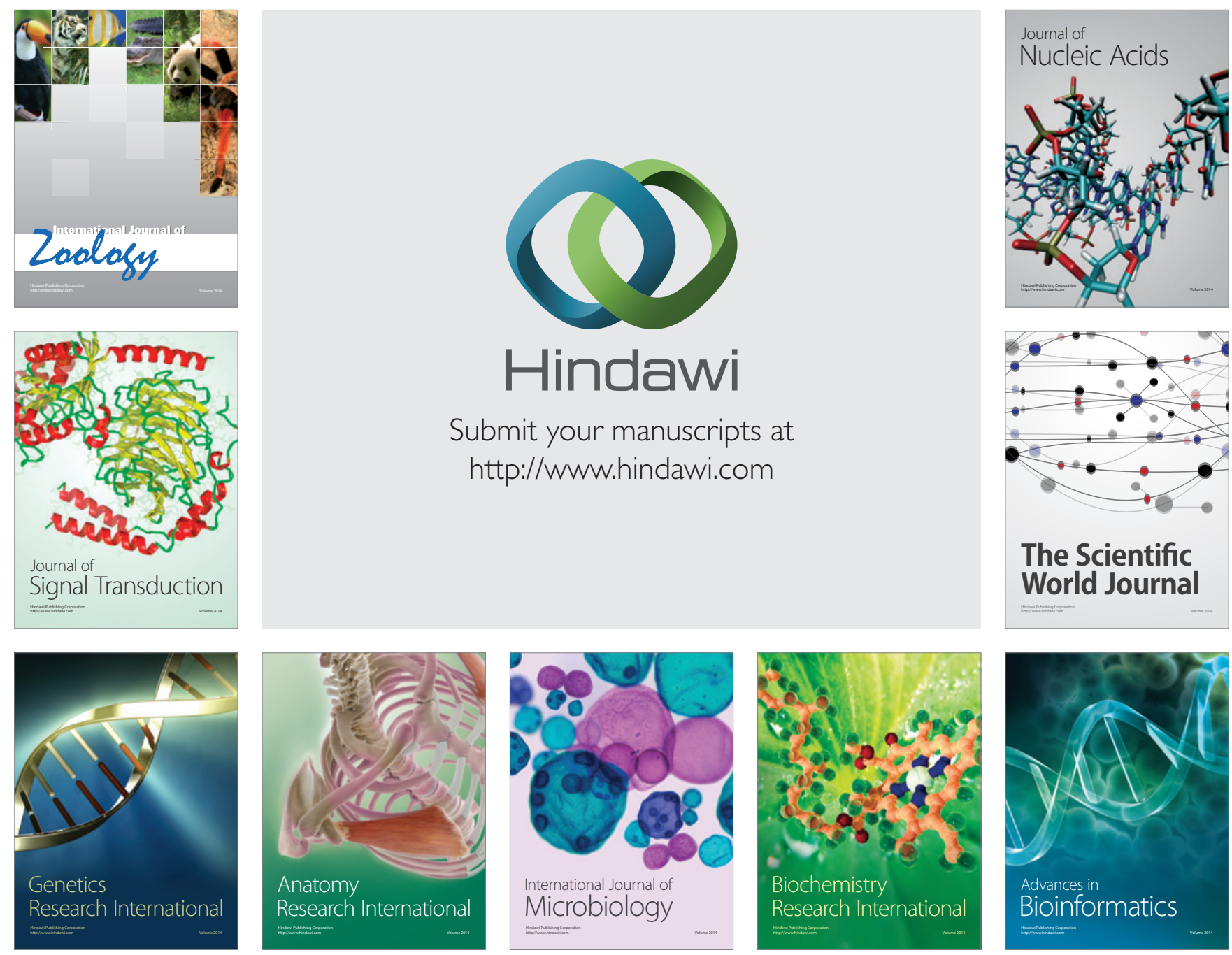

The Scientific World Journal
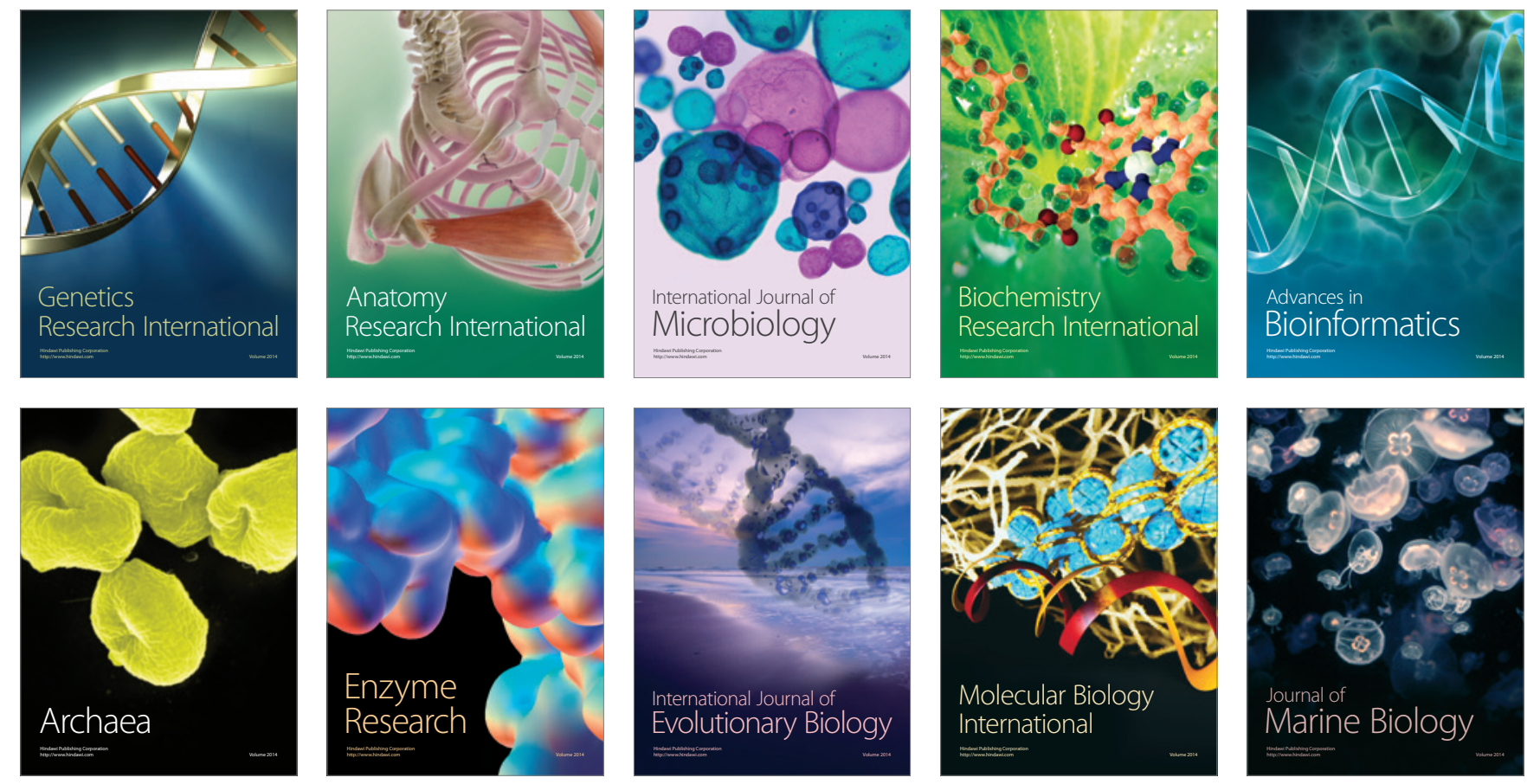